\title{
Comparative transfection of DNA into primary and transformed mammalian cells from different lineages
}

\author{
Rosalie Maurisse ${ }^{1,4}$, David De Semir ${ }^{1}$, Hamid Emamekhoo ${ }^{1,2}$, Babak Bedayat ${ }^{1,5}$, Alireza Abdolmohammadi ${ }^{1,2,6}$, \\ Hooman Parsi ${ }^{1}$, Dieter C Gruenert ${ }^{1,2,3^{*}}$
}

\begin{abstract}
Background: The delivery of DNA into human cells has been the basis of advances in the understanding of gene function and the development of genetic therapies. Numerous chemical and physical approaches have been used to deliver the DNA, but their efficacy has been variable and is highly dependent on the cell type to be transfected.

Results: Studies were undertaken to evaluate and compare the transfection efficacy of several chemical reagents to that of the electroporation/nucleofection system using both adherent cells (primary and transformed airway epithelial cells and primary fibroblasts as well as embryonic stem cells) and cells in suspension (primary hematopoietic stem/progenitor cells and lymphoblasts). With the exception of HEK 293 cell transfection, nucleofection proved to be less toxic and more efficient at effectively delivering DNA into the cells as determined by cell proliferation and GFP expression, respectively. Lipofectamine and nucleofection of HEK 293 were essentially equivalent in terms of toxicity and efficiency. Transient transfection efficiency in all the cell systems ranged from 40\%-90\%, with minimal toxicity and no apparent species specificity. Differences in efficiency and toxicity were cell type/system specific.
\end{abstract}

Conclusions: In general, the Amaxa electroporation/nucleofection system appears superior to other chemical systems. However, there are cell-type and species specific differences that need to be evaluated empirically to optimize the conditions for transfection efficiency and cell survival.

\section{Background}

Numerous chemical and physical methods have been used to introduce DNA expression vectors into mammalian cells both in vitro and in vivo, including, but not limited to, calcium phosphate precipitation, microinjection, electroporation, receptor-mediated gene transfer, particle guns, viral vectors, polyfection and lipofection [1].

The use of cationic liposome/DNA complexes (lipoplexes) and cationic polymers/DNA (polyplexes) for the transfer of genes into somatic cells has become very popular due to its limited toxicity and relative effectiveness in vitro. The ionic interaction between cationic lipids and DNA leads to the formation of lipoplexes that are generally slightly cationic. The resulting DNA/lipid

\footnotetext{
* Correspondence: dieter@cpmcri.org

${ }^{1}$ California Pacific Medical Center Research Institute, San Francisco, CA, USA
}

complexes fuse with the anionic cytoplasmic membrane and/or are introduced into the cells via an endocytic pathway [2]. The delivery of the DNA into the nucleus is still not fully understood. While transfection with cationic lipids and polymers offers some advantages over viral transduction, such as simplicity of production, low toxicity, and low immunogenicity; it has yet to reach the levels observed with viral transduction. Furthermore, the adherence of the cationic complexes to the nucleic acid can interfere with its accessibility to enzymes required for processing the DNA [3].

One of the most effective and accessible physical transfection methods, electroporation (also known as electrotransfer, electropermeabilization, or nucleofection), involves the application of brief electric pulses to cells or tissues to increase the permeability of cells to macromolecules [1,4]. The recent development of the nucleofection system has been a significant advance 
over standard electroporation systems that have been limited by high toxicity and a requirement for large numbers of cells. A number of cell lines have already been tested for their compatibility with the nucleofection system [5-12]. However, there have been no systematic studies comparing nucleofection to chemical transfection systems in various cell types across species.

In this study, chemical reagent-mediated transfection was compared to nucleofection using a number of primary and immortalized cell systems in three different mammalian species (human, rabbit, and pig) to evaluate the efficiency and toxicity. The results presented here indicate that nucleofection is more effective than chemical transfection reagents from several different cationic categories (dendrimer, polyethylenimine, lipid) at delivering DNA into a variety of different cell types. These studies also provided useful insight into transfection optimization conditions and relative cell viability for the various cells tested.

Previous studies indicated that the ratio of DNA to lipid is an important variable that determines the efficiency of transfection and the cellular toxicity $[1,13]$. To evaluate the effect of varying the ratio of DNA to transfection reagent, the cells were transfected with a constant quantity of plasmid DNA in a complex with a variable amount of a given transfection reagent. One to three different DNA/reagent ratios were evaluated for each cell system. In each case, the optimum charge ratio for a given reagent was used for the comparison with nucleofection. The nucleofection buffer and program are critical parameters for nucleofection, so different programs and buffers were tested to obtain the optimal transfection efficiency.

\section{Methods \\ Cells and Culture Conditions \\ Adherent Cells}

Primary embryonic pig fibroblasts (P16) (obtained from Dr José Cibelli, Michigan State University, East Lansing, MI) and embryonic rabbit ear fibroblasts (REF) (obtained from Dr Fuliang Du, University of Connecticut, Storrs, CT) [14] were grown in Dulbecco's Modified Eagle's Medium (DMEM) supplemented with 15\% or $10 \%$, respectively, fetal calf serum (FCS, Hyclone), 2mercaptoethanol (1.5\%), and glutamine (2 mM). Sickle cell disease (SCD) transgenic mouse embryonic stem cells (MESCs) containing a YAC carrying $240 \mathrm{kB}$ of the $\beta^{\mathrm{S}}$-globin locus (obtained from Dr YW Kan, University of California, San Francisco, CA) were grown on gelatin coated plates on a mitomycin C inactivated SNL mouse embryo fibroblast feeder layer expressing leukemia inhibitory factor (LIF) in DMEM containing and 15\% FCS (Hyclone), $2 \mathrm{mM}$ glutamine (Invitrogen), $10^{-4} \mathrm{M}$ nonessential amino acids (Invitrogen), $10^{4}$ M $\quad$ 2- mecaptoethanol (Sigma-Aldrich) [15]. Immortalized human bronchial epithelial cells (16HBE14o- $[16,17]$ and CFBE41o- [18-20]) cells and the adenovirus 5 immortalized human embryo kidney cell line, HEK 293 [21], (American Type Tissue Culture Collection, Manassas, VA) were grown on tissue culture plastic coated with an extra-cellular matrix cocktail comprised of human fibronectin (FN) (BD laboratories, NJ), Vitrogen (V) (BD laboratories), and bovine serum albumin (BSA) (Biosource/Biofluids, Camarillo, CA) (FN/V/BSA) in Minimum Essential Medium (MEM) supplemented with $10 \%$ FCS, $1 \%(\mathrm{v} / \mathrm{v})$ glutamine, $1 \%$ pen/strep [22]. Primary pig and human tracheal epithelial (PTE and HTE, respectively) cells (obtained from Dr J H Widdicombe, University of California, Davis, CA and Dr W E Finkbeiner, University of California, San Francisco, CA) were grown in modified LHC8e medium (MLHC8e): LHC8 medium (Biosource/Biofluids) supplemented with $2 \mathrm{mM}$ glutamine, $1 \mathrm{ml}$ Stock 4 solution (Biosource/Biofluids), 2 $\mu \mathrm{g} / \mathrm{ml}$ insulin (Biosource/Biofluids), $1 \mathrm{ml}$ Trace Elements solution (Biosource/Biofluids), and epinephrine $(0.5 \mu \mathrm{g} / \mathrm{ml})$ (Biosource/Biofluids) [22]. All cells were grown at $37^{\circ} \mathrm{C}$ in humidified air containing $5 \% \mathrm{CO}_{2}$ and subcultured every 2-3 days by trypsinization.

\section{Non-adherent Cells}

SC1 lymphoblasts (American Type Tissue Culture Collection, Manassas, VA, ATCC\#CRL-8756) were homozygous for the sickle cell allele) and LT1-1B1 human lymphoblasts with a $\mathrm{G}>\mathrm{C}$ substitution mutation in exon 3 in HPRT1 gene (codon 51) [23]. SC1 cells were grown in suspension culture in RPMI 1640 medium supplemented with $20 \%$ Fetal Calf Serum (ATCC) with routine media changes every $48 \mathrm{~h}$. LT1-1B1 cells were also grown in RPMI 1640 medium but supplemented with 10\% FBS (Sigma, St Louis, MO), 5 mM L-glutamine, 40 $\mathrm{mM}$ HEPES, and $10 \mathrm{mM}$ 6-thioguanine (6TG) (Sigma, company info). Hematopoietic $\mathrm{CD} 34^{+}$cells were isolated from human fetal liver (obtained from Dr M Meunch, University of California, San Francisco, CA) and grown as described previously [24] in serum-free culture medium consisting of Iscove's modified Dulbecco's medium (IMDM) (Sigma Chemical, St. Louis, MO) supplemented with 7.5 10-5 $\alpha$-thioglycerol (Sigma Chemical), $50 \mu \mathrm{g} / \mathrm{ml}$ gentamicin, 2\% fraction-V ethanol-extracted BSA (Boehringer Mannheim Biochemicals, Indianapolis, Indiana, USA), $200 \mu \mathrm{g} / \mathrm{ml}$ human iron-saturated transferrin (Boehringer Mannheim Biochemicals), $10 \mu \mathrm{g} / \mathrm{ml}$ recombinant human insulin (Boehringer Mannheim Biochemicals), and $20 \mu \mathrm{g}$ protein $/ \mathrm{ml}$ human low density lipoprotein (Sigma Chemical), $10 \mathrm{U} / \mathrm{ml}$ erythropoietin (Amgen, Thousand Oaks, CA), and $50 \mathrm{ng} / \mathrm{ml} \mathrm{c}$-kit ligand (KL) (R\&D Systems Inc., Minneapolis, MN). Cells were grown under humidified conditions in $5 \% \mathrm{CO}_{2}$ with media changes every $48 \mathrm{~h}$. 
All cells were obtained with the appropriate IRB and IACUC approvals at the institutions where they were generated. The human samples were obtained in accordance with the Helsinki Declaration http://www.wma.net/en/ 30publications/10policies/b3/index.html from autopsy material with informed consent when samples had identifiable markers. When samples were anonymous, informed consent was not required for autopsy materials or discarded tissue. Human fetal livers were obtained from midgestation fetuses after maternal consent from elective abortions. Research with fetal tissue and human tracheal epithelial cells obtained from autopsy were performed with approval of the Committee of Human Research at the University of California, San Francisco under approvals H8858-18760-04/05 and H493-27303-04, respectively.

\section{Nucleofection}

In the electroporation (nucleofection) experiments, 1 - 2 $\times 10^{6}$ cells were resuspended in $100 \mu \mathrm{l}$ of transfection buffer (Table 1). The pmaxGFP plasmid (AMAXA Biosystems, Gaithersburg, MD) that contains an enhanced green fluorescent protein $(E G F P)$ gene under regulation of a cytomegalovirus (CMV) enhancer/promoter element and is kanamycin resistant, was then added $(2 \mu \mathrm{g} /$ transfection sample) to the cell suspension. The cell/ DNA mixtures, in $1 \mathrm{~cm}$ transfection cuvettes, were nucleoporated according to a specific predefined program. Following the electroporation, the cells were incubated in their respective culture medium pre-heated to $37^{\circ} \mathrm{C}$ for $10 \mathrm{~min}$, and then seeded into cell type-specific growth medium. Unless otherwise indicated all nucleofection experiments were carried out in triplicate using 3 separate dishes for each point.

The MESCs were separated from the SNL feeder cells by short-term $(30 \mathrm{~min})$ plating of the trypsinized mixed cell population in Petri dishes not coated with gelatin. The SNL fibroblasts preferentially adhere and the MESCs are readily harvested for nucleofection.

\section{Transfection with Chemical Reagents}

Before transfection $3-5 \times 10^{5}$ cells were seeded into individual wells of 6 well plates. After a $24 \mathrm{~h}$ incubation in growth medium, the cells were exposed to the polyplexes or lipoplexes that each contained $2 \mu \mathrm{g}$ pmaxGFP plasmid/well of cells. Each transfection was carried out in triplicate and repeated 2 to 3 times. Following transfection the cells were incubated at $37^{\circ} \mathrm{C}$ in humidifiedair $\left(5 \% \mathrm{CO}_{2}\right)$ for $2 \mathrm{~h}$. The transfection medium was then removed and the cells were incubated for an additional $48 \mathrm{~h}$ in complete medium ( $2 \mathrm{ml}$ per well).

\section{Lipofectamine 2000 and Lipofectamine Plus}

Plasmid DNA and Lipofectamine 2000 (Invitrogen, Carlsbad, CA) were diluted in two independent $250 \mu \mathrm{l}$ volumes of Opti-MEM reduced serum medium (Invitrogen) without serum and mixed gently. For Lipofectamine Plus transfections, the DNA was pre-incubated with $4 \mu \mathrm{l}$ of Plus reagent and Opti-MEM to a final volume of $25 \mu \mathrm{l}$. After a $5 \mathrm{~min}$ incubation at room temperature, the DNA and the Lipofectamine 2000 in OptiMEM were combined and incubated for an additional $20 \mathrm{~min}$ at room temperature to allow the DNA-Lipofectamine 2000 complexes to form. The DNA- Plus mix $(25 \mu \mathrm{l})$ was added to an equal volume the Lipofectamine 2000 reagent mixed with Opti-MEM and incubated for an additional $30 \mathrm{~min}$ at room temperature. The DNALipofectamine 2000 complexes were then added to each well containing cells and medium. The vol/wt ratios of Lipofectamine 2000/DNA were: $3 / 1,5 / 1$ and $7 / 1$, and $1 /$ 1 for Lipofectamine Plus/DNA.

\section{Polyethylenimine (PEI)}

PEI (QBiogene, Morgan Irvine, CA) and plasmid DNA were each diluted with equal volumes of $150 \mathrm{mM} \mathrm{NaCl}$. The DNA solution was then added to the PEI solution, and after a 20 min incubation at room temperature, 200 $\mu \mathrm{l} /$ well aliquots of the DNA-PEI complexes were added to cells grown in serum containing medium in

Table 1 Cells and Optimal Nucleofection Conditions

\begin{tabular}{|c|c|c|c|c|}
\hline Species & Cell name & Cell description & AMAXA program & AMAXA buffer \\
\hline \multirow[t]{2}{*}{ Pig } & P16 & Pig Fetal Fibroblasts & $\mathrm{U}-20$ & NHDF \\
\hline & PTE & Primary Pig Tracheal Epithelial Cells & $\mathrm{T}-20$ & Basic epithelial cell \\
\hline \multirow[t]{7}{*}{ Human } & 16HBE41o- & Immortalized Human Bronchial Epithelial cell Line (WT) & O-17 & $\mathrm{V}$ \\
\hline & CFBE410- & Immortalized Human CF Bronchial Epithelial Cell Line ( $(\mathrm{F} 508 / \Delta \mathrm{F} 508))$ & O-17 & $\mathrm{V}$ \\
\hline & HTE & Primary Human Tracheal Epithelial Cells & $\mathrm{T}-20$ & Basic epithelial cell \\
\hline & LT1-1B1 & Immortalized Human Lymphoblasts (HPRT mutant) & G-16 & $\mathrm{T}$ \\
\hline & SC-1 & Immortalized Human Lymphoblasts ( $\beta^{\mathrm{S}}$-globin mutant) & G-16 & $\bar{T}$ \\
\hline & $\mathrm{HSPC}$ & Primary Hematopoietic Stem/Progenitor Cells (CD34+ lin-) & $\mathrm{U}-08$ & CD34+ \\
\hline & HEK 293 & Adenovirus immortalized human embryonic kidney cells & $x-01$ & $\mathrm{~V}$ \\
\hline Rabbit & REF & Rabbit Ear Fibroblasts & $\mathrm{U}-23$ & NHDF \\
\hline Mouse & MESC & Transgenic mouse embryonic stem cells ( $\beta^{S}$-globin mutant) & A-24 & Mouse ES cell \\
\hline
\end{tabular}

The table contains the cells used in the studies and their origin. For each cell line/type, the optimal nucleofection program and buffer are indicated. 
individual wells. The charge ratios (+/-) of PEI nitrogen residues/DNA phosphates were: $3 / 1,5 / 1$ and $8 / 1$

\section{Effectene}

Effectene transfections were conducted according to the manufacturer's instructions (Qiagen, Valencia, CA). The $\mathrm{vol} / \mathrm{wt}$ ratios of Effectene/DNA were 10/1 and 25/1.

\section{Analysis of transfected cells}

Cells were harvested $48 \mathrm{~h}$ post-transfection, washed, and resuspended in PBS. In adherent cell cultures, only cells adhering to the culture dish before trypsinization were counted as viable. Cells in suspension were exposed to PBS containing $0.02 \%$ EGTA and $1 \mu \mathrm{g} / \mathrm{ml}$ propidium iodide to identify the nonviable cells through propidium iodide fluorescence. The cells were then sorted by flow cytometry, evaluated with the Cellquest software (BD Biosciences, San Jose, CA) to determine the proportion of fluorescent cells.

The cells were transfected with a reporter plasmid encoding the EGFP using either nucleofection or four different chemical reagents (Effectene, Lipofectamine 2000, Lipofectamine Plus and PEI). Transfection efficiency was determined $48 \mathrm{~h}$ after transfection as the:

(\# of EGFP positive cells ${ }^{\mathrm{a}}$ ) / (total \# of cells transfected ${ }^{\mathrm{a}}$ ).

The percent cytotoxicity following transfection was:

$$
(\mathrm{C}-\mathrm{B}) / \mathrm{C} \times(100)=\mathrm{T}
$$

Where $\mathrm{B}=$ the \# of adherent or total \# of cells when grown in suspension, in the transfected sample at the time of harvest, $\mathrm{C}=$ \# of nontransfected adherent or total \# of cells when grown in suspension, present at the time of harvest, and $\mathrm{T}$ is toxicity.

Cell viability is therefore the number of viable transfected cells present at the $48 \mathrm{~h}$ post-transfection harvest time compared to control, non-transfected cells, i.e., the percent viability $(\mathrm{V})$ is:

$$
\mathrm{V}=100-\mathrm{T} .
$$

This proportion of live cells present at the time of harvest was taken to be an indicator of relative cell cytotoxicity and consequently, the cell viability following transfection.

\section{Results \\ Nucleofection \\ Pig and Rabbit Fetal Fibroblasts}

The ability to generate transgenic animals through somatic cell nuclear transfer (SCNT) has opened up many possibilities for the study of disease and the development of therapies [25]. Pig fetal fibroblasts (P16) previously used for SCNT (J Cibelli, personal communication) were transfected using 30 different nucleofection programs in combination with the AMAXA NHDF buffer to determine the optimal parameters for nucleofection. Program U-20 was the most effective and resulted in a 90\% efficiency of GFP expression and $5 \%$ cytotoxicity (Figure 1). The most effective program/buffer combination for rabbit embryo fibroblasts (REF) transfection was program U-23 with the NHDF buffer (Table 1). After 48 h, GFP expression was observed in $38 \%$ of the cells (Figure 1).

\section{Human and Pig Primary Tracheal Epithelial cells}

Primary airway epithelial cells play a crucial role in the study of airway disease and infection. The ability to efficiently transfer of genes into these cells is critical in evaluating the mechanisms underlying airway epithelial cell function and airway disease pathology. Because there was no optimized protocol available for nucleofection of primary human or pig tracheal epithelial cells, 3 different buffers were tested (EP-39, EP-42 and E-58 (Basic Epithelial Cell buffer)). Optimization of the human tracheal epithelial (HTE) cells involved pairing each buffer with 9 different programs. The optimal transfection efficiency was achieved using program T-20 and the Amaxa Basic Epithelial Cell buffer and resulted in $47 \%$ expression efficiency and $83 \%$ cytotoxicity $(17 \%$ viability) (Figure 1, Table 1).

Nucleofection of primary pig tracheal epithelial (PTE) cells under the same conditions, i.e., using the same buffer and program, gave a transfection efficiency of $90 \%$. The $5 \%$ cytotoxicity (95\% viability) of the transfected PTE cells detected $48 \mathrm{~h}$ after transfection was considerably less than that observed with the HTE cells (Figure 1)

\section{Human Bronchial Epithelial Cell Lines}

Immortalized bronchial epithelial cells [26-28] were studied, because they are routinely used as models of cystic fibrosis (CF) and airway disease. Normal, 16HBE14o[16], and CF, CFBE41o- [17-20], cell lines were optimally transfected with buffer $\mathrm{V}$ and program $\mathrm{O}-17$ (Table 1). The 16HBE14o- cells showed a $62 \%$ viability and $65 \%$ transfection efficiency, while transfection of the CFBE 410 - cells gave $81 \%$ expression efficiency at $50 \%$ viability (Figure 1).

\section{Hematopoietic Stem/Progenitor Cells}

Hematopoietic stem/progenitor cells (HSPCs) are attractive targets for gene delivery and therapy because of their potential for self-renewal and multilineage differentiation $[29,30]$. These properties make them ideally suited for ex vivo gene transfer that could result in a treatment for numerous inherited and/or hematologic disorders.

HSPCs isolated from fetal liver [24] were nucleofected using Amaxa CD34 buffer and program U-08 (Table 1). GFP was expressed in $55 \%$ of the HSPCs accompanied by a viability of $50 \%$. Furthermore, the ability of the 


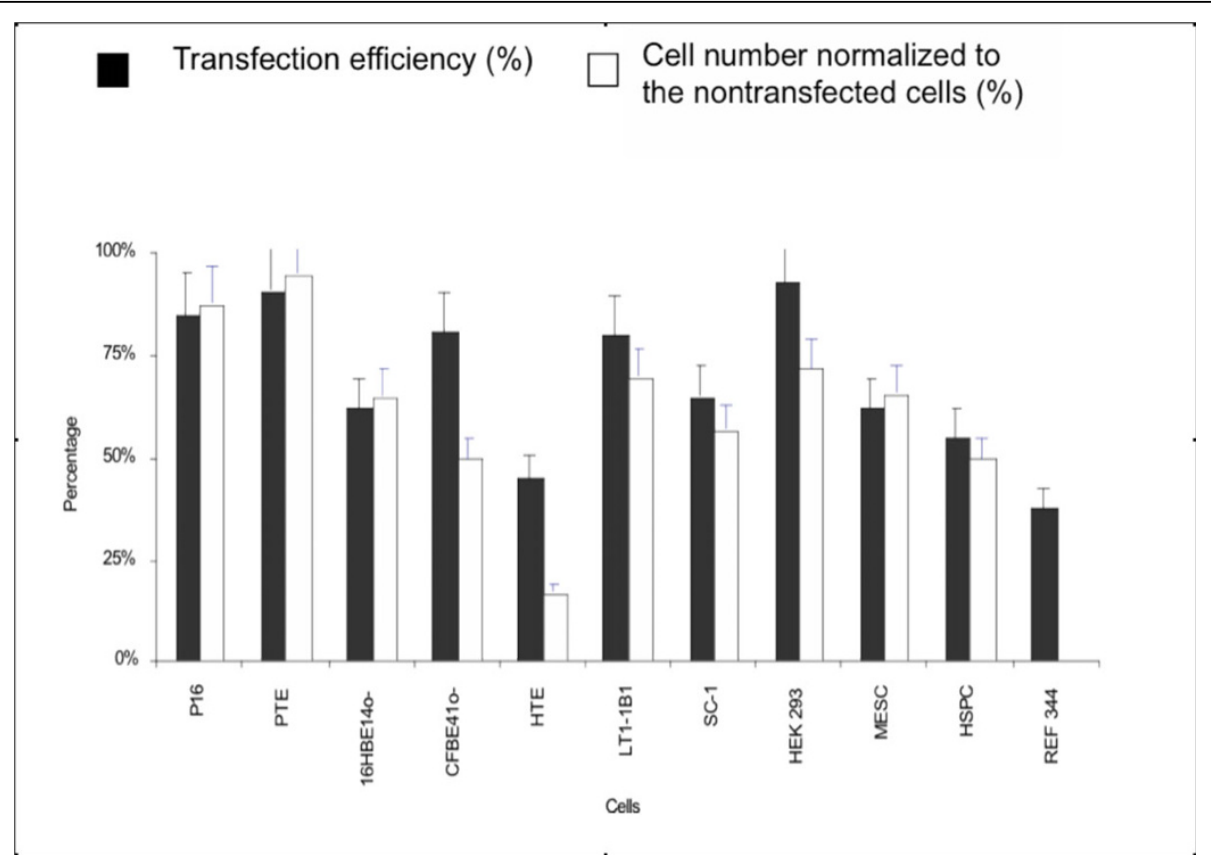

Figure 1 The transfection efficiency obtained 48 hours after nucleofection of $10^{6}$ cells with $\mathbf{2} \boldsymbol{\mu g}$ of pmaxGFP plasmid. The cells are described in Table 1. The error bars represent the standard error of the mean (SEM), with $n=3$.

HSPCs to differentiate into red blood cells persisted after transfection when the cells were grown in differentiating medium ( $\mathrm{R}$ Maurisse and DC Gruenert, unpublished data).

\section{Lymphoblasts}

Epstein-Barr virus (EBV) transformed lymphocytes (lymphoblasts) were nucleofected with buffer $\mathrm{T}$ and program G-16 (Table 1). The transfection efficiency of two different lymphoblast lines (SC-1 and LT1-1B1) was 75\% with an $80 \%$ viability (Figure 1 ).

\section{Mouse Embryonic Stem Cells}

Transgenic mouse embryonic stem cells (MESCs) that contain a YAC that carries $240-\mathrm{kb} \beta^{\mathrm{S}}$-globin gene family [15] were optimally transfected using the Amaxa MESC buffer with program A-24 (Table 1). The transfection efficiency and viability was $62 \%$ and $66 \%$, respectively (Figure 1). The cells were not effectively transfected using chemical reagents due to high cytotoxicity and/or senescence following reagent exposure (H Emamekhoo and DC Gruenert, unpublished observations).

\section{HEK 293 Cells}

The HEK 293 (human embryonic kidney) cell lines was nucleofected with Amaxa buffer V and program X-01 (Table 1). The efficiency of transfection and the viability were $93 \%$ and $72 \%$, respectively (Figure 1).

\section{Nucleofection vs Chemical Transfection}

A number of chemical reagents were used to transfect 5 $\times 10^{5}$ cells with $2 \mu \mathrm{g}$ of pmaxGFP plasmid. The transfection efficiencies and the viabilities were then compared to those observed for nucleofection of the same cell lines/types (Figure 2). The quantity of plasmid per cell transfected with the chemical transfection reagent was two-fold more than that used for nucleofection. For each reagents one to three reagent/DNA ratios were tested either as a ratio of $\mathrm{vol} / \mathrm{wt}$ ( $\mu \mathrm{l}$ reagents/ $\mu \mathrm{g}$ DNA); Effectene: 10/1 and 25/1; Lipofectamine 2000: 3/ 1, 5/1 and 7/1; Lipofectamine Plus $1 / 1$. The reagent/ DNA ratios evaluated for PEI were based on positive and negative charges. The charge ratios (Nitrogen residues/Phosphate) evaluated was: $3 / 1,5 / 1$ and $8 / 1$ PEI.

Only the optimal, i.e., in terms of transfection efficiency, reagent/DNA ratios were compared (Figure 2). The data presented compares the relative effectiveness of plasmid delivery into pig fetal fibroblast (P16) as well as primary human and pig tracheal epithelial cells (HTE and PTE, respectively) by chemical reagents and nucleofection.

\section{Pig Fetal Fibroblasts}

P16 cells were transfected with $2 \mu \mathrm{g}$ of pmaxGFP plasmid. The transfection efficiencies were 18\% (Effectene 25/1), 28\% (Lipofectamine 2000; 7/1), 20\% (Lipofectamine Plus) and 32\% (PEI; 3/1) (Figure 2-A). Transfection by nucleofection gave an efficiency of $85 \%$.

\section{Pig Tracheal Epithelial Cells}

PTE were transfected with $2 \mu \mathrm{g}$ pmaxGFP plasmid in a complex with Effectene, Lipofectamine 2000, Lipofectamine Plus and PEI (Figure 2-B). The transfection efficiencies of the PTE cells were 5\% (Effectene; 25/1), 30\% 


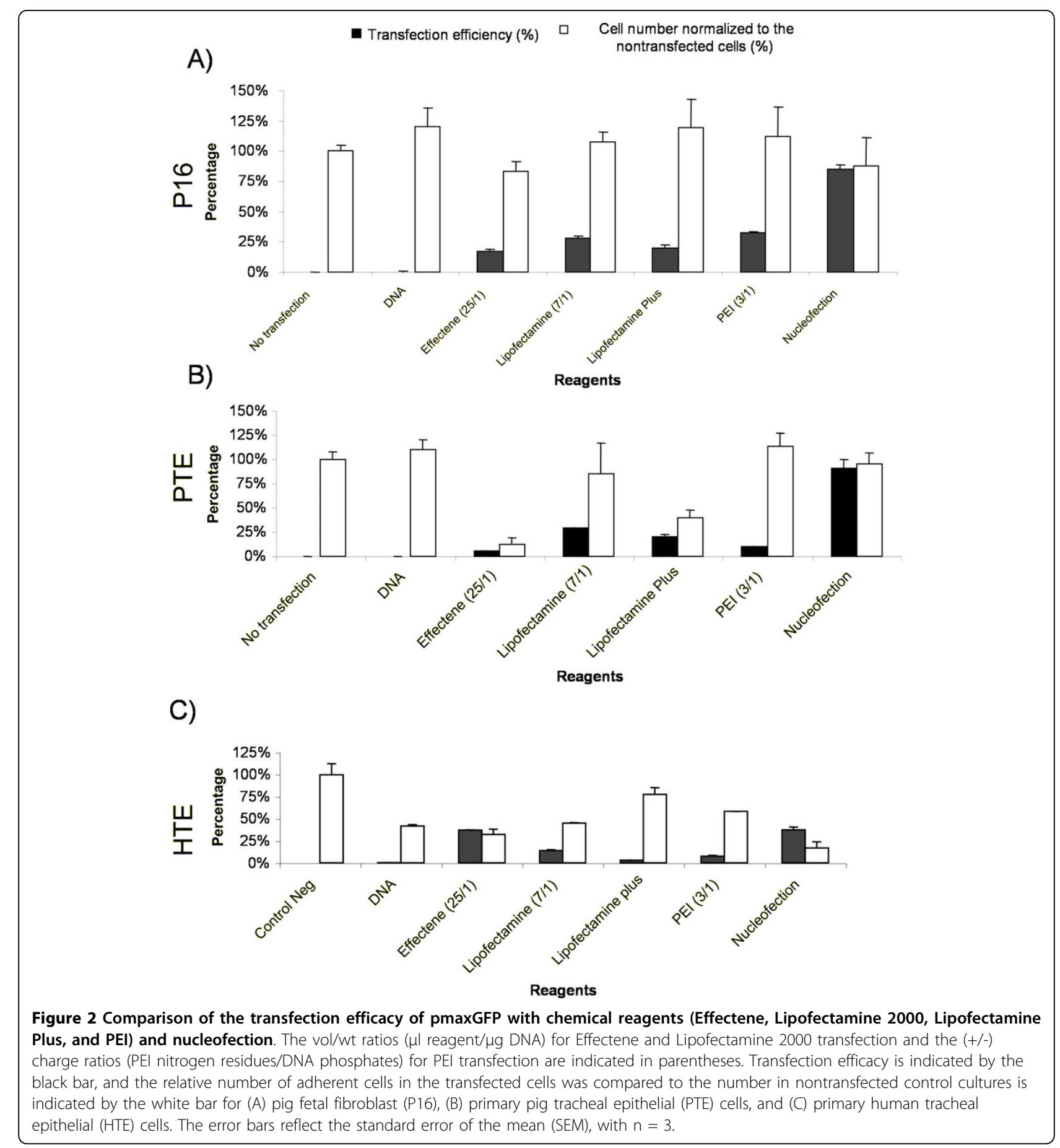

(Lipofectamine 2000; 7/1), 21\% (Lipofectamine Plus) and $10 \%$ (PEI; 3/1) transfection respectively at the ratio indicated (Figure 2). The nucleofection resulted in a transfection efficiency of $90 \%$ and cytotoxicity of $5 \%$.

\section{Human Tracheal Epithelial Cells}

HTE cells were transfected with the four reagents indicated below and by nucleofection (Figure 2-C). The transfection efficiencies obtained were: 37\% (Effectene;
25/1), 14\% (Lipofectamine 2000; 7/1), 3\% (Lipofectamine Plus; $1 / 1$ ), and $8 \%$ (PEI; 3/1), respectively (Figure 2C). Nucleofection gave a transfection efficiency of $45 \%$.

\section{HEK 293 Cells}

The transfection efficiency and viability with Lipofectamine 2000 was $98 \%$ and $67 \%$, respectively. The transfection efficiency with Lipofectamine Plus was $82 \%$ with a viability of $80 \%$ (data not shown). 


\section{Discussion}

The delivery of genes into primary and immortalized cell lines is an underpinning of mammalian molecular biology and has become increasingly important in biomedical research and therapeutic development. Defining the parameters necessary for transfection optimization is, thus a critical element in further enhancing gene delivery efficacy in a wide range of cells. While there has been significant work done in the development of chemical and viral reagents for the delivery of recombinant DNA, only limited improvements have been made in physical delivery systems [1]. The development of a novel electroporation system by AMAXA has shown considerable promise as a system for delivering DNA to a broad range of cell lines and cell systems that grow either as adherent monolayers or in suspension [7,31-34]. A number of cell lines from human and animals that have been particularly important for characterization of airway diseases such as cystic fibrosis and asthma, for somatic cell nuclear transfer, for the study of hematopoietic diseases, and for mutation analysis were evaluated and compared for their ability to be efficaciously transfected with the nucleofection system. With the exception of HEK293 cells, when compared to chemical DNA delivery vehicles, nucleofection appears to be, in general, more effective and less toxic. The transfection efficiency and toxicity is equivalent following nucleofection or Lipofectamine transfection of HEK293 cells (Figure 1).

Transfection of two immortalized human airway epithelial cell lines, 16HBE14o- and CFB41o- and primary airway epithelial cells from pig and human (PTE and HTE, respectively) showed that nucleofection was more effective than the four chemical reagents tested with the exception of the HTE cells that were also effectively transfectable with Effectene. Primary human airway epithelial cells were difficult to transfect even by nucleofection (45\%) when compared to the PTE (95\%). While the reason for this difference is not certain, it is possible that cells at different passages or in different stages of differentiation will have varying responses to insult. Additional studies will need to be undertaken to determine whether the transfection efficiency and viability following nucleofection can be further enhanced.

The development of somatic cell nuclear transfer using fetal fibroblast as donor cells has played a central role in the cloning of animals such as the pig and the rabbit [14,35-37]. Greater than $95 \%$ of the P16 cells expressed GFP following nucleofection while the rabbit ear fibroblasts (REF) appeared to be more recalcitrant to transfection and gave a GFP expression frequency in the range of $40 \%$. This difference may be due to species-specific factors that affect the transport and/or of expression the plasmid DNA in the cell nucleus. In addition, differences in the age of the cultured cells, and cell density may also play a factor. These elements need to be considered when optimizing transfection conditions and should be addressed empirically.

Suspension cultures of hematopoietic origin have been notoriously difficult to transfect with chemical reagents and have had to rely on viral vector systems to facilitate DNA delivery [1]. However, the studies here showed that nucleofection was able to transfect both primary human hematopoietic stem/progenitor cells as well as immortalized lymphoblasts giving levels GFP expression in the range of $60-80 \%$ with relatively low levels of cytotoxicity. Thus, nucleofection may be an effective means of ex vivo genetic modification of hematopoietic stem cells that have multilineage potential.

Embryonic stem (ES) cells have become increasingly more important due their potential for organ regeneration and for the development of models to study disease. Mouse ES cells (MESCs) have been notoriously difficult to transfect with chemical reagents, and have thus been relegated to transfection by electroporation. Standard electroporation protocols have resulted in high levels of cytotoxicity that have undermined the ability to transfer genes into the cells and the potential of the MESCs to produce viable embryos or differentiate in a lineage directed fashion. The nucleofection system has provided the opportunity to overcome some of these issues by enhancing transfection efficacy and MESC viability. As indicated by the studies presented here, MESCs can be routinely transfected at efficiencies of about $60 \%$ with a concurrent $60 \%$ viability. These observations have important implications for the transfection of human ES cells and for their genetic modification and directed differentiation in that nucleofection has the potential of producing genetically modified cells that can be phenotypically manipulated without losing their pluripotency.

\section{Conclusion}

This study demonstrates the nucleofection system is effective for a broad range of cell lines and cell types, resulting in high levels of transgene expression and low toxicity. Not only is it superior when compared to various commercially available chemical DNA delivery vehicles in terms of transfection efficacy and viability, it also has potential therapeutic applications in ex vivo gene delivery.

\section{Abbreviations}

ATCC: American Type Tissue Culture Collection; CF: cystic fibrosis; CFBE: CF bronchial epithelial; CMV: cytomegalovirus; DMEM: Dulbecco's modified Eagle's medium; EBV: Epstein-Barr virus; EGFP: enhanced green fluorescent protein; ES: embryonic stem; FCS: fetal calf serum; FN/N/BSA: fibronectin/ Vitrogen/bovine serum albumin; HSPC: hematopoietic stem/progenitor cells; HBE: human bronchial epithelial; HEK: human embryo kidney; HPRT: 
hypoxanthine phosphoribosyl transferase; HTE: human tracheal epithelial; IMDM: Iscove's modified Dulbecco's medium; KL: c-kit ligand; LIF: leukemia inhibitory factor; MEM: minimal essential medium; MESC: mouse ES cells; PBS: phosphate buffered saline; PEI: polyethylenimine; PTE: pig tracheal epithelial; REF: rabbit embryo fibroblasts; SCD: sickle cell disease; 6-TG: 6 thioguanine; YAC: yeast artificial chromosome.

\section{Acknowledgements}

We would like to acknowledge Dr Jose Cibelli for the pig fetal fibroblasts, Dr Fuliang Du for the rabbit ear fibroblasts, Dr Jonathan Widdicombe for the primary pig and and Dr Walter Finkbeiner for the primary human tracheal epithelial cells, Dr Marcus Meunch for his assistance in obtaining the human hematopoietic stem/progenitor cells, and Dr YW Kan for the transgenic mouse ES cells. This work was supported by NIH grants DK66403, GM75111, and HL80814 as well as grants from the Cystic Fibrosis Foundation, Pennsylvania Cystic Fibrosis, Inc., and the California Pacific Medical Center Research Foundation. AA and HE received support from NIH Training Grant, DK007636.

\section{Author details}

${ }^{1}$ California Pacific Medical Center Research Institute, San Francisco, CA, USA. ${ }^{2}$ Department of Laboratory Medicine, University of California San Francisco, San Francisco, CA, USA. 'Department of Medicine, University of Vermont, Burlington, VT, USA. ${ }^{4}$ Current address: Medicen, 6 rue Alexandre Cabanel, 75015 Paris, France. ${ }^{5}$ Current address: Department of Anesthesiology and Critical Care, Massachusetts General Hospital, Harvard Medical School, Boston, MA, USA. ${ }^{6}$ Current address: Department of Internal Medicine, Good Samaritan Hospital, Cincinnati, OH, USA.

\section{Authors' contributions}

RM - designed and conducted experiments with epithelial cells, HSPCs and calibrated Amaxa system and EGFP analysis, analyzed and compiled data, wrote initial draft of manuscript. DD - designed and conducted experiments with REF and transformed cells, analyzed data, edited manuscript. HE designed and calibrated experiments with HSPCs and assisted with HEK and lymphoblast studies, analyzed data. BB - designed and calibrated experiments with LT1-1B1 lymphoblasts, analyzed data. AA - designed and calibrated experiments with SC-1 lymphoblasts, analyzed data. HP - designed and conducted experiments with HEK cells, analyzed and compiled data. DCG - designed entire project, coordinated research efforts, analyzed data, wrote and edited manuscript, finalized manuscript. All authors have read and approved of the final manuscript.

Received: 18 June 2009

Accepted: 8 February 2010 Published: 8 February 2010

\section{References}

1. Colosimo A, Goncz KK, Holmes AR, Kunzelmann K, Novelli G, Malone RW, Bennett MJ, Gruenert DC: Transfer and expression of foreign genes in mammalian cells. Biotechniques 2000, 29(2):314-318, 320-312, 324 passim.

2. Wagner E, Culmsee C, Boeckle S: Targeting of Polyplexes: Toward Synthetic Virus Vector Systems. Adv Genet 2005, 53PA:333-354.

3. Colosimo A, Goncz KK, Novelli G, Dallapiccola B, Gruenert DC: Targeted correction of a defective selectable marker gene in human epithelial cells by small DNA fragments. Mol Ther 2001, 3(2):178-185.

4. Zimmermann U: Electric field-mediated fusion and related electrical phenomena. Biochim Biophys Acta 1982, 694:227-277.

5. Kobayashi N, Rivas-Carrillo JD, Soto-Gutierrez A, Fukazawa T, Chen Y Navarro-Alvarez N, Tanaka N: Gene delivery to embryonic stem cells. Birth Defects Res C Embryo Today 2005, 75(1):10-18.

6. Lorenz $P$, Harnack U, Morgenstern R: Efficient gene transfer into murine embryonic stem cells by nucleofection. Biotechnol Lett 2004, 26(20):1589-1592.

7. Maasho K, Marusina A, Reynolds NM, Coligan JE, Borrego F: Efficient gene transfer into the human natural killer cell line, NKL, using the Amaxa nucleofection system. J Immunol Methods 2004, 284(1-2):133-140.

8. Martinet W, Schrijvers DM, Kockx MM: Nucleofection as an efficient nonviral transfection method for human monocytic cells. Biotechnol Lett 2003, 25(13):1025-1029.
9. Nakashima S, Matsuyama Y, Nitta A, Sakai Y, Ishiguro N: Highly efficient transfection of human marrow stromal cells by nucleofection. Transplant Proc 2005, 37(5):2290-2292.

10. Quenneville SP, Chapdelaine P, Rousseau J, Beaulieu J, Caron NJ, Skuk D, Mills P, Olivares EC, Calos MP, Tremblay JP: Nucleofection of musclederived stem cells and myoblasts with phiC31 integrase: stable expression of a full-length-dystrophin fusion gene by human myoblasts. Mol Ther 2004, 10(4):679-687.

11. Radons J, Gross C, Stangl S, Multhoff G: Nucleofection of non-B cells with mini-Epstein-Barr virus DNA. J Immunol Methods 2005, 303(1-2):135-141.

12. Schakowski F, Buttgereit $P$, Mazur M, Marten A, Schottker B, Gorschluter M, Schmidt-Wolf IG: Novel non-viral method for transfection of primary leukemia cells and cell lines. Genet Vaccines Ther 2004, 2(1):1.

13. Felgner JH, Kumar R, Sridhar CN, Wheeler CJ, Tsai YJ, Border R, Ramsey P, Martin M, Felgner PL: Enhanced gene delivery and mechanism studies with a novel series of cationic lipid formulations. J Biol Chem 1994, 269(4):2550-2561.

14. Liu JL, Sung LY, Du F, Julian M, Jiang S, Barber $M$, Xu J, Tian XC, Yang $X$ : Differential development of rabbit embryos derived from parthenogenesis and nuclear transfer. Mol Reprod Dev 2004, 68(1):58-64.

15. Chang JC, Ye L, Kan YW: Correction of the sickle cell mutation in embryonic stem cells. Proc Natl Acad Sci USA 2006, 103(4):1036-1040.

16. Cozens AL, Yezzi MJ, Kunzelmann K, Ohrui T, Chin L, Eng K, Finkbeiner WE, Widdicombe JH, Gruenert DC: CFTR expression and chloride secretion in polarized immortal human bronchial epithelial cells. Am J Respir Cell Mol Biol 1994, 10(1):38-47.

17. Gruenert DC, Willems M, Cassiman JJ, Frizzell RA: Established cell lines used in cystic fibrosis research. J Cyst Fibros 2004, 3(Suppl 2):191-196.

18. Bruscia E, Sangiuolo F, Sinibaldi P, Goncz KK, Novelli G, Gruenert DC: Isolation of CF cell lines corrected at DeltaF508-CFTR locus by SFHRmediated targeting. Gene Ther 2002, 9(11):683-685.

19. Ehrhardt C, Collnot EM, Baldes C, Becker U, Laue M, Kim KJ, Lehr CM: Towards an in vitro model of cystic fibrosis small airway epithelium: characterisation of the human bronchial epithelial cell line CFBE410. Cell Tissue Res 2006, 323(3):405-415.

20. Illek B, Maurisse R, Wahler L, Kunzelmann K, Fischer H, Gruenert DC: Cl transport in complemented CF bronchial epithelial cells correlates with CFTR mRNA expression levels. Cell Physiol Biochem 2008, 22:57-68.

21. Graham FL, Smiley J, Russell WC, Nairn R: Characteristics of a human cell line transformed by DNA from human adenovirus type 5. $J$ Gen Virol 1977, 36(1):59-74.

22. Gruenert $D C$, Basbaum $C B$, Widdicombe JH: Long-term culture of normal and cystic fibrosis epithelial cells grown under serum-free conditions. In Vitro Cell Dev Biol 1990, 26(4):411-418.

23. Branda RF, O'Neill JP, Brooks EM, Trombley LM, Nicklas JA: The effect of folate deficiency on the cytotoxic and mutagenic responses to ethyl methanesulfonate in human lymphoblastoid cell lines that differ in p53 status. Mutat Res 2001, 473(1):51-71.

24. Muench MO, Suskind DL, Barcena A: Isolation, growth and identification of colony-forming cells with erythroid, myeloid, dendritic cell and NKcell potential from human fetal liver. Biol Proced Online 2002, 4:10-23.

25. Kues WA, Anger M, Carnwath JW, Paul D, Motlik J, Niemann H: Cell cycle synchronization of porcine fetal fibroblasts: effects of serum deprivation and reversible cell cycle inhibitors. Biol Reprod 2000, 62(2):412-419.

26. Gruenert DC: Differentiated properties of human epithelial cells trnsformed in vitro. BioTechniques 1987, 5:740-749.

27. Gruenert DC, Basbaum CB, Welsh MJ, Li M, Finkbeiner WE, Nadel JA: Characterization of human tracheal epithelial cells transformed by an origin-defective simian virus 40. Proc Natl Acad Sci USA 1988, 85(16):5951-5955.

28. Gruenert DC, Finkbeiner WE, Widdicombe JH: Culture and transformation of human airway epithelial cells. Am J Physiol 1995, 268(3 Pt 1):L347-360.

29. Krause DS: Plasticity of marrow-derived stem cells. Gene Ther 2002, 9(11):754-758.

30. Krause DS, Theise ND, Collector MI, Henegariu O, Hwang S, Gardner R, Neutzel S, Sharkis SJ: Multi-organ, multi-lineage engraftment by a single bone marrow-derived stem cell. Cell 2001, 105(3):369-377.

31. Leclere PG, Panjwani A, Docherty R, Berry M, Pizzey J, Tonge DA: Effective gene delivery to adult neurons by a modified form of electroporation. $J$ Neurosci Methods 2005, 142(1):137-143. 
32. Gresch O, Engel FB, Nesic D, Tran TT, England HM, Hickman ES, Korner I, Gan L, Chen S, Castro-Obregon S, Hammermann R, Wolf J, MullerHartmann H, Nix M, Siebenkotten G, Kraus G, Lun K: New non-viral method for gene transfer into primary cells. Methods 2004, 33(2):151-163.

33. Haleem-Smith H, Derfoul A, Okafor C, Tuli R, Olsen D, Hall DJ, Tuan RS: Optimization of high-efficiency transfection of adult human mesenchymal stem cells in vitro. Mol Biotechnol 2005, 30(1):9-20

34. Lenz P, Bacot SM, Frazier-Jessen MR, Feldman GM: Nucleoporation of dendritic cells: efficient gene transfer by electroporation into human monocyte-derived dendritic cells. FEBS Lett 2003, 538(1-3):149-154.

35. Chesne P, Adenot PG, Viglietta C, Baratte M, Boulanger L, Renard JP: Cloned rabbits produced by nuclear transfer from adult somatic cells. Nat Biotechnol 2002, 20(4):366-369.

36. De Sousa PA, Dobrinsky JR, Zhu J, Archibald AL, Ainslie A, Bosma W, Bowering J, Bracken J, Ferrier PM, Fletcher J, Gasparrini B, Harkness L, Johnston P, Ritchie M, Ritchie WA, Travers A, Albertini D, Dinnyes A, King TJ, Wilmut I: Somatic cell nuclear transfer in the pig: control of pronuclear formation and integration with improved methods for activation and maintenance of pregnancy. Biol Reprod 2002, 66(3):642-650.

37. Wolf DP, Mitalipov S, Norgren RB Jr: Nuclear transfer technology in mammalian cloning. Arch Med Res 2001, 32(6):609-613.

doi:10.1186/1472-6750-10-9

Cite this article as: Maurisse et al:: Comparative transfection of DNA into primary and transformed mammalian cells from different lineages. BMC Biotechnology 2010 10:9.

\section{Submit your next manuscript to BioMed Central} and take full advantage of:

- Convenient online submission

- Thorough peer review

- No space constraints or color figure charges

- Immediate publication on acceptance

- Inclusion in PubMed, CAS, Scopus and Google Scholar

- Research which is freely available for redistribution

Submit your manuscript at www.biomedcentral.com/submit
Biomed Central 